\title{
Rheumatoid Arthritis, as a Clinical Disease, but Not Rheumatoid Arthritis-associated Autoimmunity is Linked to Cardiovascular Events
}

Helene Gouze ( $\nabla$ helene.gouze@aphp.fr)

Hôpital Ambroise-Pare https://orcid.org/0000-0002-5333-0316

Philippe Aegerter

Department of Public Health and Biostatistics, UMR1168, INSERM/UVSQ-Paris Saclay University, France

Roula Said-Nahal

Ambroise Paré University Hospital: Centre Hospitalier Universitaire Ambroise Pare

Marie Zins

Population-based Cohorts Unit UMS 011, Paris University, Villejuif, France

Marcel Goldberg

Population-based Cohorts Unit UMS 011, Paris University, Villejuif, France

Guillaume Morelle

Ambroise Paré University Hospital: Centre Hospitalier Universitaire Ambroise Pare

Georg Schett

Friedrich Alexander University Erlangen Nuremberg: Friedrich-Alexander-Universitat Erlangen-Nurnberg

Maxime Breban

Ambroise Paré University Hospital: Centre Hospitalier Universitaire Ambroise Pare

Maria-Antonietta D’Agostino

Università Cattolica del Sacro Cuore: Universita Cattolica del Sacro Cuore

\section{Research article}

Keywords: rheumatoid arthritis, cardiovascular risk, cardiovascular diseases, autoimmunity, anticitrullinated protein autoantibody

Posted Date: August 9th, 2021

DOI: https://doi.org/10.21203/rs.3.rs-744938/v1

License: (c) (i) This work is licensed under a Creative Commons Attribution 4.0 International License.

Read Full License 
Version of Record: A version of this preprint was published at Arthritis Research \&amp; Therapy on February 24th, 2022. See the published version at https://doi.org/10.1186/s13075-022-02722-z. 


\section{Abstract}

Background: Rheumatoid Arthritis (RA) is characterized by increased cardiovascular (CV) mortality. CV events are particularly high in patients with RA-specific autoimmunity, including rheumatoid factor (RF) and anti-citrullinated protein antibodies (ACPA), raising the question whether RA-specific autoimmunity itself is associated with CV events.

Methods: New CV events (myocardial infarction, stroke or death by CV cause) were recorded in 20,625 subjects of the Electricité de France - Gaz de France (GAZEL) cohort. Self-reported RA cases in the GAZEL cohort were validated by phone interview on the basis of a specific questionnaire. In 1,618 subjects, in whom serum was available, RF and ACPA were measured. A piecewise exponential Poisson regression was used to analyze the association of $\mathrm{CV}$ events with presence of RA as well as RA-specific autoimmunity (without RA).

Results: CV events in GAZEL were associated with age, male sex, smoking, hypertension, hyperlipidemia and diabetes mellitus (HR from 1.06 to 1.87, p < 0.05). Forty-two confirmed RA cases were identified. Confirmed RA was significantly associated with CV risk increase (HR of 3.03; 95\% Cl: 1.13-8.11, p=0.03) independently of conventional CV risk factors. One hundred seventy-eight subjects showed RF or ACPA positivity without presence of RA. CV events were not associated with ACPA positivity (HR: $1.52,95 \% \mathrm{Cl}$ : $0.47-4.84, p=0.48$ ) or RF positivity (HR: $1.15,95 \% \mathrm{Cl}: 0.55-2.40, p=0.70)$ in the absence of RA.

Conclusions: RA, as a clinical chronic inflammatory disease, but not mere positivity for RF or ACPA in the absence of clinical disease is associated with increased CV risk.

\section{Introduction}

Rheumatoid Arthritis (RA) is an autoimmune chronic inflammatory disease characterized by synovitis leading to joint destruction and functional impairment (1). Prevalence of RA is around $0.5 \%$ in Caucasian population (2). RA development is promoted by a combination of genetic susceptibility and

environmental factors that leads to breech of immune tolerance and formation of autoantibodies such as Rheumatoid Factor (RF) and Anti-Citrullinated Peptide Antibodies (ACPA) (1). Autoimmunity precedes RA by several years (positive predictive value $>96 \%$ at 5 years) $(3-5)$ and is associated with higher disease activity and structural damage $(6,7)$.

RA is characterized by an increased morbidity and mortality (8-11). Besides structural damage and its consequences on disability, increased cardiovascular (CV) risk, including myocardial ischemia and heart failure, has been described in RA (10). Aside from the consequences from disability and infections, CV disease is responsible for increased mortality in RA (8-11). Increased CV risk in RA does not only seem to be explained by standard CV risk factors, but also by chronic inflammation, which accelerates the process of atherosclerosis $(12,13)$. This process seems to be independent from the use of concomitant treatments such as corticosteroids or non-steroidal anti-inflammatory drugs (NSAIDs), which also add to CV risk (14). 
In recent years, several studies suggested that RA with positive RF and/or ACPA presents a higher CV risk $(9,15-18)$. Thus, one may think that RF and ACPA could influence $C V$ risk independently from RA. However, evidence that CV disease may be linked to the presence of autoantibodies, independent from the occurrence of RA, is scarce, and only one study suggested that autoimmunity increases CV risk (15, $16,19)$ in a subpopulation of African-American women, but not in all women with positive autoantibodies (19). To try to explore this question, we made use of a large epidemiological cohort study (20-22) and separately tested the influence of RA on CV risk as well as the impact of autoantibodies (RF/ACPA) without presence of RA on CV risk.

\section{Methods}

\section{Study population}

The GAZEL cohort was started in 1989 and included 20,625 current employees at that time of the French national company of services named "Electricité de France - Gaz de France" $(20,21)$. Women were aged between 35 and 50 years and men between 40 and 50 years at inclusion, respectively. Demographic characteristics and a complete medical history were recorded in all subjects at baseline. Thereafter, subjects received an annual questionnaire covering information on a large spectrum of pathologies, including rheumatic and musculoskeletal diseases (RMDs) as well as CV risk factors $(20,21)$. In addition, plasma was collected from a fraction of the GAZEL cohort between 2000 and 2005. In 2010, a specific screening questionnaire dedicated to identify patients affected with inflammatory joint disorders, including RA, was included in the GAZEL workup.

The GAZEL protocol was approved by the French authority for data confidentiality ('Commission Nationale Informatique et Liberté') and by the Ethics Evaluation Committee of the 'Institut National de la Santé et de la Recherche Médicale (INSERM)' (IRB0000388, FWA00005831).

\section{RA diagnosis ascertainment}

All subjects who declared to suffer from RA in the 2010 screening questionnaire were included in the procedure. After having accepted to be contacted, patients were reached by phone and interviewed by an experienced rheumatologist trained for this purpose using a phone questionnaire specifically developed for ascertaining the diagnosis of RA (See Additional file 1). This questionnaire had first been validated on a panel of 102 consecutive outpatients consulting for any rheumatic disease (including RA, axial spondyloarthritis or psoriatic arthritis) in the Rheumatology Department of Ambroise Paré Hospital (Boulogne-Billancourt, France). The questionnaire was administrated by a physician blinded to the patients' diagnosis and its sensitivity and specificity for the diagnosis of RA were estimated to $100 \%$ and 89\%, respectively (See Additional file 1).

\section{ACPA and RF determination}

Aliquots of plasma stored at $-80^{\circ} \mathrm{C}$ were used to quantify the presence of ACPA and RF antibodies. Laboratory tests were realized in a specialized research laboratory (Department of Immunology and 
Internal Medicine, University of Erlangen-Nuremberg) and consisted in IgG ACPA ELISA (Reference Euroimmun EA 1505-9601 G) and IgM-RF ELISA (Reference IBL International RE70341). Cut-off value for ACPA was defined as positive if $\geq 4.6 R U / m L$, and for $R F$ if $\geq 10 U / m L$.

\section{Statistical analysis}

Clinical and biological parameters (age, sex, CV risk factors, including high blood pressure, smoking habit, alcohol intake, obesity, diabetes, dyslipidemia, death), and the occurrence of CV events, including myocardial ischemia, non-lethal stroke, and death due to CV cause were reported using descriptive statistics (mean and standard deviation or median and interquartile range). The outcome variable was the occurrence of new CV event, including non-lethal myocardial ischemia, non-lethal stroke or death due to $\mathrm{CV}$ disease. Explanatory variables were multiple and concerned RA, autoantibodies (ACPA and RF) and already known $\mathrm{CV}$ risk factors. Cut-off values defining risk factors were considered as follows: presence of obesity if body mass index (BMI) $\geq 30$, alcohol intake if $\geq 14$ glasses per week for women and $\geq 21$ glasses per week for men, tobacco consumption if number of pack-years (PY) $\geq 20$. Family history of myocardial infarction was considered when it occurred before the age of 60 years (mother) or 50 years (father). As blood samples were collected between 2000 and 2005 and death causes were available until 2014, the analysis concerned the occurrence of new CV events from 2005 to 2014 . We used piecewise exponential Poisson regression, as the data were composed of discrete times of observation (23). High blood pressure, dyslipidemia, diabetes, BMI, tobacco and alcohol intakes were accounted as timedependent covariates. Subjects who declared having RA but who were not reached by phone to confirm their diagnosis were excluded from the analyses. A sensitivity analysis was performed to compare subjects with available plasma sample and subjects without.

\section{Results}

\section{Identification of CV events}

GAZEL cohort enrolled 20,625 subjects, including 5,614 women (27.2\%) and 15,011 men (72.8\%). Mean \pm SD age at inclusion was $44.2 \pm 3$ years. Characteristics of the cohort at the beginning of the analysis period (2005) are reported in Table 1. From 2005 to 2014, a mean of 169 CV events occurred every year in the whole cohort. During this observation period, 1,687 subjects in the whole cohort presented a new CV event, 129 of them were lethal and 1,558 not lethal. 
Table 1

Demographic and clinical characteristics of GAZEL subjects in 2005

\begin{tabular}{|c|c|c|c|}
\hline Variable & $\begin{array}{l}\text { Global cohort } \\
(\mathrm{N}=19,557)\end{array}$ & $\begin{array}{l}\text { Non-collected* } \\
\text { subjects }(\mathrm{N}= \\
17,939)\end{array}$ & $\begin{array}{l}\text { Collected* } \\
\text { subjects }(\mathrm{N}= \\
1,618)\end{array}$ \\
\hline Mean age (years) & $60.2 \pm 3.49$ & $60.1 \pm 3.51$ & $60.6 \pm 3.25$ \\
\hline Sex (\% men) & $\begin{array}{l}72.4 \%(71.7- \\
73 \%)\end{array}$ & $71.5 \%(70.8-72.1 \%)$ & $\begin{array}{l}82.1 \%(80.1- \\
83.9 \%)\end{array}$ \\
\hline Mean retirement age (years) & $55.3 \pm 3$ & $55.3 \pm 3.1$ & $55.4 \pm 2.6$ \\
\hline $\begin{array}{l}\text { GAZEL } 2005 \text { questionnaire response } \\
\text { rate }\end{array}$ & $\begin{array}{l}74 \%(73.4- \\
74.7 \%)\end{array}$ & $72 \%(71.3-72.6 \%)$ & $97 \%(96-97.7 \%)$ \\
\hline \multicolumn{4}{|l|}{ CV risk factors } \\
\hline Hypertension & $\begin{array}{l}17.3 \%(16.8- \\
17.9 \%)\end{array}$ & $17.1 \%(16.6-17.7 \%)$ & $\begin{array}{l}19.4 \%(17.5- \\
21.4 \%)\end{array}$ \\
\hline Diabetes & $\begin{array}{l}4.1 \%(3.8- \\
4.4 \%)\end{array}$ & $4.1 \%(3.8-4.4 \%)$ & $4.4 \%(3.5-5.6 \%)$ \\
\hline Hyperlipidemia & $\begin{array}{l}20.5 \%(19.9- \\
21 \%)\end{array}$ & $19.8 \%(19.3-20.4 \%)$ & $27.2 \%(25-29.4 \%)$ \\
\hline $\begin{array}{l}\text { Family history of myocardial } \\
\text { infarction }\end{array}$ & $\begin{array}{l}6.5 \%(6.1- \\
6.8 \%)\end{array}$ & $6.4 \%(6-6.8 \%)$ & $7.2 \%(6-8.6 \%)$ \\
\hline Body mass index & $26 \pm 3.7$ & $26 \pm 3.7$ & $25.6 \pm 3.3$ \\
\hline Smoking ( $\% \geq 20$ pack-years) & $\begin{array}{l}23.2 \%(22.6- \\
23.7 \%)\end{array}$ & $23.4 \%(22.8-24 \%)$ & $\begin{array}{l}20.1 \%(18.2- \\
22.2 \%)\end{array}$ \\
\hline \multicolumn{4}{|l|}{$\begin{array}{l}\% \geq \text { to } 21 \text { glasses/week (men) } \% \geq \text { to } \\
14 \text { glasses/week (women) }\end{array}$} \\
\hline \multicolumn{4}{|l|}{ CV events } \\
\hline All events & $\begin{array}{l}1.7 \%(1.5- \\
1.8 \%)\end{array}$ & $1.7 \%(1.5-1.9 \%)$ & $1.3 \%(0.8-2 \%)$ \\
\hline Stroke & $\begin{array}{l}0.5 \%(0.4- \\
0.6 \%)\end{array}$ & $0.5 \%(0.4-0.6 \%)$ & $0.4 \%(0.1-0.8 \%)$ \\
\hline Myocardial infarction & $1.2 \%(1-1.3 \%)$ & $1.2 \%(1-1.4 \%)$ & $0.9 \%(0.5-1.5 \%)$ \\
\hline \multicolumn{4}{|c|}{$\begin{array}{l}\text { *Collected subjects: those with available blood sample for ACPA/RF testing. Results are expressed as } \\
\text { mean (standard deviation) or percentage }(95 \% \mathrm{Cl})\end{array}$} \\
\hline (This table should appear at the begin & of the results & t). & \\
\hline
\end{tabular}


From the 18,752 subjects still followed in 2010, year in which the questionnaire on RMDs was administrated, 13,960 replied to that questionnaire. 421 subjects defined themselves to have RA. Of these 421 subjects, 197 were reached by phone and RA diagnosis was confirmed in 42 and dismissed in 155 of them (See flowchart Fig. 1). Among 42 confirmed RA, 30 were men and 12 were women with a mean \pm SD age of $61.2 \pm 3.4$ years. Median RA duration was 9 years (range: $1-43$ years). There was no significant difference at baseline between RA patients and the whole cohort (in 2005).

Among RA patients, 13 had an available plasma sample. Treatment information was available for 30 of them: $87 \%$ received at least one disease modifying anti-rheumatic drug (DMARD) (26/30). Among them, $69 \%$ had only conventional synthetic DMARDs (18/26), $8 \%$ had only biological DMARDs (2/26) and $23 \%$ received both (6/26). Patients treated with corticosteroids represented 30\% (9/30 patients), $78 \%$ of them took $<8 \mathrm{mg}$ per day of prednisone.

\section{Association between RA and CV events}

RA was significantly associated with an increased incidence of $\mathrm{CV}$ events in both univariate and multivariate analyses, with a hazard ratio (HR) of 3.03 (95\% Cl: $1.13-8.11, \mathrm{p}=0.03$, multivariate analysis) (Table 2). CV events were also associated with established CV risk factors, such as male sex (HR: 1.87, 95\% Cl: 1.5-2.34, p<0.001), tobacco consumption (HR: 1.54, 95\% Cl: 1.31-1.80, p<0.001), high blood pressure (HR: 1.51, 95\% Cl: 1.30-1.76, $p<0.001$ ), diabetes (HR: 1.25, 95\% Cl: 1.00-1.56, $p=0.05$ ), dyslipidemia (HR: 1.19, 95\% Cl: 1.03-1.38, $\mathrm{p}=0.02$ ) and age (HR: 1.06, 95\% Cl: 1.04-1.09, p < 0.001), but not obesity, which was found significantly associated only in the univariate analysis (HR: $1.49,95 \% \mathrm{Cl}$ : $1.24-1.79, p<0.001)$. In contrast, alcohol consumption was protective, with an HR of 0.72 (95\% Cl: $0.58-$ $0.88, p=0.001)$. 
Table 2

Independent association between rheumatoid arthritis (RA) and incidence of cardiovascular events in the whole GAZEL cohort

\begin{tabular}{|c|c|c|c|c|}
\hline \multirow[t]{2}{*}{ Variable } & \multicolumn{2}{|l|}{ Univariate analysis } & \multicolumn{2}{|c|}{ Multivariate analysis } \\
\hline & $\mathrm{HR}(95 \% \mathrm{Cl})$ & $P$ & $\mathrm{HR}(95 \% \mathrm{Cl})$ & $\mathrm{p}$ \\
\hline Confirmed RA & $3.11(1.17-8.32)$ & 0.02 & $3.03(1.13-8.11)$ & 0.03 \\
\hline Gender (male) & $2.37(1.92-2.94)$ & $<0.001$ & $1.85(1.50-2.34)$ & $<0.001$ \\
\hline Tobacco consumption ( $\geq 20 \mathrm{PY}$ ) & $1.84(1.58-2.15)$ & $<0.001$ & $1.54(1.31-1.80)$ & $<0.001$ \\
\hline High blood pressure & $1.78(1.54-2.06)$ & $<0.001$ & $1.51(1.30-1.76)$ & $<0.001$ \\
\hline Diabetes & $1.72(1.39-2.13)$ & $<0.001$ & $1.25(1.00-1.56)$ & 0.05 \\
\hline Dyslipidemia & $1.40(1.21-1.62)$ & $<0.001$ & $1.19(1.03-1.38)$ & 0.02 \\
\hline Obesity (BMI $\geq 30$ ) & $1.49(1.24-1.79)$ & $<0.001$ & $1.17(0.97-1.43)$ & 0.11 \\
\hline $\begin{array}{l}\text { Parental antecedent of } \\
\text { myocardial infarction }\end{array}$ & $1.17(0.93-1.47)$ & 0.18 & $1.11(0.88-1.40)$ & 0.37 \\
\hline Age (years) & $1.09(1.07-1.12)$ & $<0.001$ & $1.06(1.04-1.09)$ & $<0.001$ \\
\hline Alcohol consumption & $0.83(0.68-1.02)$ & 0.07 & $0.72(0.58-0.88)$ & 0.001 \\
\hline
\end{tabular}

(This table should appear in results part next to the session "Association between RA and CV events").

\section{Identification of autoantibody-positive individuals}

Plasma samples were available in 1,618 subjects of the GAZEL cohort. As compared to the non-collected cohort, collected subjects had a similar prevalence of CV events including stroke and myocardial infarction. Also CV risk factors were comparable between non-collected and collected subjects. Only dyslipidemia and alcohol consumption were slightly higher in the collected subjects (Table 1). With respect to the RA validation questionnaire, 9 RA patients were identified among the collected subjects. Besides, 179 (11.1\%) of the 1,609 collected subjects without RA had either positive ACPA or RF $(\mathrm{N}=8)$, ACPA only $(N=37)$ or $R F$ only $(N=134)$. All 9 RA patients were autoantibody positive $(N=8$ ACPA $+R F+$; $\mathrm{N}=1$ ACPA + ).

\section{Association between RA-specific autoantibodies and CV events}

The association between ACPA and CV risk was studied in non-RA subjects who had positive ACPA and/or RF ( $\mathrm{N}=179)$. No association was observed between the occurrence of CV events and ACPA positivity in those subjects (HR: 1.52, 95\% Cl: $0.47-4.84, \mathrm{p}=0.48$, multivariate analysis) (Table 3 ). 
Similarly, no association was observed between RF positivity and CV events (HR: 1.15, 95\% Cl: 0.55-2.40, $p=0.70)$.

Table 3

Association of ACPA or RF positivity (without RA) with incident CV events in subjects with stored serum

\begin{tabular}{|lllll|}
\hline Variable & Univariate analysis & \multicolumn{3}{l}{ Multivariate analysis } \\
\hline Presence of ACPA & $\mathrm{HR}(95 \% \mathrm{Cl})$ & $\mathrm{P}$ & $\mathrm{HR}(95 \% \mathrm{Cl})$ & $\mathrm{P}$ \\
\hline Presence of RF & $2.07(0.84-5.11)$ & 0.12 & $1.52(0.47-4.84)$ & 0.48 \\
\hline Other factors & $1.55(0.49-4.90)$ & 0.46 & $1.15(0.55-2.40)$ & 0.70 \\
\hline Gender (male) & & & & \\
\hline Age (years) & $1.86(0.90-3.87)$ & 0.09 & $1.20(0.57-2.55)$ & 0.63 \\
\hline High blood pressure & $1.17(1.09-1.26)$ & $<0.001$ & $1.14(1.06-1.23)$ & $<0.001$ \\
\hline Diabetes & $2.19(1.40-3.42)$ & $<0.001$ & $1.87(1.17-2.96)$ & 0.008 \\
\hline Dyslipidemia & $1.26(0.55-2.90)$ & 0.59 & $0.84(0.35-2.01)$ & 0.70 \\
\hline Obesity (BMI $\geq 30)$ & $1.57(1.01-2.45)$ & 0.50 & $1.42(0.90-2.24)$ & 0.13 \\
\hline Tobacco consumption & $1.14(0.57-2.29)$ & 0.71 & $0.87(0.42-1.78)$ & 0.70 \\
\hline ( 20 PY) & $2.21(1.39-3.50)$ & $<0.001$ & $1.87(1.16-3.02)$ & 0.01 \\
\hline Alcohol consumption & $0.91(0.51-1.62)$ & 0.75 & $0.78(0.43-1.39)$ & 0.39 \\
\hline Parental antecedent of & $1.01(0.47-2.20)$ & 0.97 & $0.85(0.39-1.86)$ & 0.69 \\
\hline myocardial infarction & & & & \\
\hline
\end{tabular}

This analysis only concerned the collected subjects (i.e. those with available blood sample for ACPA/RF testing), without RA $(\mathrm{N}=1,609)$

(This table should appear in results part next to the session "Association between RA-specific autoantibodies and CV events").

\section{Discussion}

This study shows that RA, as a clinical disease, but not RA-related autoimmunity is associated with CV events. It is known that RA is associated with two-fold increased risk for CV disease compared to the general population (24-26). While the overall CV risk in RA patients is based on traditional risk factors as well as immune changes related to RA, the excess risk of RA is usually considered to be based on increased inflammation and/or autoimmunity (24). While elevated systemic markers of inflammation have shown to be associated with a higher CV risk (27), other studies have also reported that CV risk is higher in RA patients with positive ACPA (15-18), but such observation could be related to the severity of 
RA correlating with ACPA positivity (28), rather than to an independent association with ACPA. Hence, disentangling the effect of autoimmunity from the one of inflammation on CV risk in RA population is difficult, if not impossible.

The fact that ACPA and RF positivity precedes RA and that some individuals are positive for RF or ACPA without even developing the disease allows to separately assess the role of RA-related autoimmunity and $\mathrm{RA}$, as an inflammatory joint disease, on CV risk (4-6). The analysis of GAZEL individuals that were positive for RF and/or ACPA permitted to directly evaluate the association between ACPA/RF and CV without the influence of arthritis. This analysis clearly showed that RA-related autoimmunity is not associated with an increased risk for $\mathrm{CV}$ disease, indicating that systemic inflammation is required for precipitating CV events. Hence, it is conceivable that effector function of autoantibodies, i.e. Fc- mediated cytokine release, which translates asymptomatic autoimmunity to inflammatory disease is critical for conveying CV risk (29).

In the GAZEL cohort, traditional risk factors such as male sex, age smoking, hypertension, hyperlipidemia and diabetes mellitus were independently associated with CV events. Notably, presence of RA was significantly associated with CV disease with a hazard ratio of 3.0. The strength of the association between $\mathrm{CV}$ events and RA is reflected by the fact that the number of ascertained RA cases was rather low in this cohort but nonetheless this association was robust. This observation also supports the robustness of the lack of association between autoantibodies and CV risk as the numbers of autoantibody positive subjects was much higher than the one with RA. The overall low number of ascertained RA cases can be explained by the fact that participants of the GAZEL cohort were mostly males ( $>70 \%$ ). Considering a prevalence of RA of $0.5 \%$ in the French population (2), that only up to $1 / 3$ of RA patients being males and that not all subjects with self-reported RA could be validated, the numbers of observed and established RA cases fits the numbers of expected RA cases.

Strength of this study includes the fact that the increased risk of CV events in RA patients as compared to controls was confirmed in the same cohort and that also the associations between RA and CV events on one hand, and autoantibodies and CV events in the other were assessed in the same cohort. Another strength is that the ascertainment of RA cases did not rely merely on self-reporting but was confirmed by experienced rheumatologist, using a dedicated questionnaire that was developed and validated for this purpose. The only study which assessed the association between both ACPA and RF in non-RA patients is the one demonstrating that the presence of autoantibodies was associated with $\mathrm{CV}$ risk increased in African American women, and the diagnosis of RA was based on self-reporting information (19). Limitations are the fact that plasma was not available in the entire GAZEL cohort and hence autoantibody data were only obtained in a fraction of the cohort. On the other hand, subjects with plasma did not essentially differ from the others with respect to demographic characteristics, CV risk factors and $\mathrm{CV}$ events. Furthermore, the robustness of a lack of association between autoantibodies and CV events is supported by the fact that positive association could be observed for RA, despite the number of RA cases was substantially lower than the number of subjects positively tested for autoantibodies. 


\section{Conclusion}

These data show that $\mathrm{CV}$ risk in RA is dependent on the inflammatory disease itself, while the mere presence of RA-related autoimmunity is not associated with CV disease. Thus the higher risk for CV events in autoantibody-positive RA is likely related to a more severe and chronic course of the disease rather than direct effects of autoantibodies on the vessels. These data support the observations that effective control of inflammation may lower CV risk $(30,31)$.

\section{Abbreviations}

ACPA: Anti-Citrullinated Peptide Antibodies

CV: Cardiovascular

DMARDs: Disease Modifying Anti-Rheumatic Drugs

RA: Rheumatoid Arthritis

RF: Rheumatoid Factor

\section{Declarations}

\section{Ethics approval and consent to participate}

The GAZEL protocol was approved by the French authority for data confidentiality ('Commission Nationale Informatique et Liberté') and by the Ethics Evaluation Committee of the 'Institut National de la Santé et de la Recherche Médicale (INSERM)' (IRB0000388, FWA00005831).

\section{Consent for publication}

Not applicable.

\section{Availability of data and materials}

The data that support the findings of this study are available from Cohortes team of the Unit UMS 011 Paris University - Inserm - Versailles St-Quentin-Paris-Saclay University but restrictions apply to the availability of these data, which were used under license for the current study, and so are not publicly available. Data are however available from the authors upon reasonable request and with permission of Cohortes team of the Unit UMS 011 Paris University - Inserm - Versailles St-Quentin-Paris-Saclay University responsible for the GAZEL database management. 


\section{Competing interests}

The authors declare no conflicts of interest.

\section{Funding}

No specific funding was received from any bodies in the public, commercial or not-for-profit sectors to carry out the work described in this article.

\section{Authors' contributions}

$H G, P A, M B$ and MADA analyzed and interpreted the data and drafted the manuscript. GS performed the autoantibodies quantification, contributed to data interpretation and manuscript writing. GM and RSN performed the validation process of diagnosis. MZ and MG are responsible for the GAZEL database management and contributed to data interpretation and manuscript writing. All authors contributed, read and approved the final version of the manuscript.

\section{Acknowledgments}

We express our thanks to the Cohort team of the Unit UMS 011 Paris University - Inserm - Versailles StQuentin-Paris-Saclay University responsible for the GAZEL database management. The GAZEL Cohort Study was funded by EDF-GDF and INSERM, and received grants from the 'Cohortes Santé TGIR Program', Agence nationale de la recherché (ANR) and Agence française de sécurité sanitaire de l'environnement et du travail (AFSSET)".

\section{References}

1. Mclnnes IB, Schett G. The pathogenesis of rheumatoid arthritis. N Engl J Med. 2011 Dec;8(23):220519. 365.

2. Guillemin F. Prevalence of rheumatoid arthritis in France: 2001. Ann Rheum Dis. 2005 Oct 1;64(10):1427-30.

3. Aho K, Heliövaara M, Maatela J, Tuomi T, Palosuo T. Rheumatoid factors antedating clinical rheumatoid arthritis. J Rheumatol. 1991 Sep;18(9):1282-4.

4. Berglin E, Padyukov L, Sundin U, Hallmans G, Stenlund H, Van Venrooij WJ, et al. A combination of autoantibodies to cyclic citrullinated peptide (CCP) and HLA-DRB1 locus antigens is strongly associated with future onset of rheumatoid arthritis. Arthritis Res Ther. 2004;6(4):R303-8.

5. Nielen MMJ, van Schaardenburg D, Reesink HW, van de Stadt RJ, van der Horst-Bruinsma IE, de Koning MHMT, et al. Specific autoantibodies precede the symptoms of rheumatoid arthritis: A study of serial measurements in blood donors. Arthritis Rheum. 2004 Feb;50(2):380-6. 
6. van Gaalen FA, Linn-Rasker SP, van Venrooij WJ, de Jong BA, Breedveld FC, Verweij CL, et al. Autoantibodies to cyclic citrullinated peptides predict progression to rheumatoid arthritis in patients with undifferentiated arthritis: A prospective cohort study. Arthritis Rheum. 2004 Mar;50(3):709-15.

7. Harre U, Georgess D, Bang H, Bozec A, Axmann R, Ossipova E, et al. Induction of osteoclastogenesis and bone loss by human autoantibodies against citrullinated vimentin. J Clin Invest. 2012 May;122(5):1791-802.

8. van den Hoek J, Boshuizen HC, Roorda LD, Tijhuis GJ, Nurmohamed MT, van den Bos G. a. M, et al. Mortality in patients with rheumatoid arthritis: a 15-year prospective cohort study. Rheumatol Int. 2017 Apr;37(4):487-93.

9. Sparks JA, Chang S-C, Liao KP, Lu B, Fine AR, Solomon DH, et al. Rheumatoid Arthritis and Mortality Among Women During 36 Years of Prospective Follow-Up: Results From the Nurses' Health Study. Arthritis Care Res. 2016;68(6):753-62.

10. Gabriel SE. Cardiovascular Morbidity and Mortality in Rheumatoid Arthritis. Am J Med. 2008 Oct;121(10):9-14.

11. Gabriel SE, Crowson CS, Kremers HM, Doran MF, Turesson C, O'Fallon WM, et al. Survival in rheumatoid arthritis: A population-based analysis of trends over 40 years. Arthritis Rheum. 2003 Jan;48(1):54-8.

12. Hannawi S, Haluska B, Marwick TH, Thomas R. Atherosclerotic disease is increased in recent-onset rheumatoid arthritis: a critical role for inflammation. Arthritis Res Ther. 2007;9(6):R116.

13. Mahmoudi M, Aslani S, Fadaei R, Jamshidi AR. New insights to the mechanisms underlying atherosclerosis in rheumatoid arthritis. Int J Rheum Dis. 2017;20(3):287-97.

14. Aviña-Zubieta JA, Abrahamowicz M, De Vera MA, Choi HK, Sayre EC, Rahman MM, et al. Immediate and past cumulative effects of oral glucocorticoids on the risk of acute myocardial infarction in rheumatoid arthritis: a population-based study. Rheumatol Oxf Engl. 2013 Jan;52(1):68-75.

15. Barbarroja N, Pérez-Sanchez C, Ruiz-Limon P, Castro-Villegas C, Aguirre MA, Carretero R, et al. Anticyclic citrullinated protein antibodies are implicated in the development of cardiovascular disease in rheumatoid arthritis. Arterioscler Thromb Vasc Biol. 2014 Dec;34(12):2706-16.

16. Arnab B, Biswadip G, Arindam P, Shyamash M, Anirban G, Rajan P. Anti-CCP antibody in patients with established rheumatoid arthritis: Does it predict adverse cardiovascular profile? J Cardiovasc Dis Res. 2013 Jun;4(2):102-6.

17. Goodson NJ, Wiles NJ, Lunt M, Barrett EM, Silman AJ, Symmons DPM. Mortality in early inflammatory polyarthritis: Cardiovascular mortality is increased in seropositive patients. Arthritis Rheum. 2002 Aug;46(8):2010-9.

18. Turk SA, Heslinga M, Twisk J, van der Lugt V, Lems WF, van Schaardenburg D, et al. Change in cardiovascular risk after initiation of anti-rheumatic treatment in early rheumatoid arthritis. Clin Exp Rheumatol. 2019 Jun;37(3):513.

19. Majka DS, Chang RW, Pope RM, Teodorescu MC, Karlson EW, Vu THT, et al Autoantibodies are associated with subclinical atherosclerosis and cardiovascular endpoints in caucasian and african 
american women in a prospective study: The multi-ethnic study of atherosclerosis (MESA). Arthritis Rheum. 2012;64((Majka DS, Chang RW, Liu K) Northwestern University, Chicago, IL, United States):S711.

20. Goldberg M, Leclerc A, Bonenfant S, Chastang JF, Schmaus A, Kaniewski N, et al. Cohort profile: the GAZEL Cohort Study. Int J Epidemiol. 2007 Feb;36(1):32-9.

21. Goldberg M, Leclerc A, Zins M. Cohort Profile Update: The GAZEL Cohort Study. Int J Epidemiol. 2015 Feb;44(1):77-7g.

22. Meneton P, Lemogne $C$, Herquelot E, Bonenfant S, Larson MG, Vasan RS, et al. A Global View of the Relationships between the Main Behavioural and Clinical Cardiovascular Risk Factors in the GAZEL Prospective Cohort. PloS One. 2016;11(9):e0162386.

23. Li Y, Panagiotou OA, Black A, Liao D, Wacholder S. Multivariate piecewise exponential survival modeling. Biometrics. 2016 Jun;72(2):546-53.

24. Agca R, Heslinga SC, Rollefstad S, Heslinga M, Mclnnes IB, Peters MJL, et al. EULAR recommendations for cardiovascular disease risk management in patients with rheumatoid arthritis and other forms of inflammatory joint disorders: 2015/2016 update. Ann Rheum Dis. 2017 Jan;76(1):17-28.

25. Avina-Zubieta JA, Thomas J, Sadatsafavi M, Lehman AJ, Lacaille D. Risk of incident cardiovascular events in patients with rheumatoid arthritis: a meta-analysis of observational studies. Ann Rheum Dis. 2012 Sep;71(9):1524-9.

26. Nikiphorou E, de Lusignan S, Mallen CD, Khavandi K, Bedarida G, Buckley CD, et al. Cardiovascular risk factors and outcomes in early rheumatoid arthritis: a population-based study. Heart Br Card Soc. 2020 Oct;106(20):1566-72.

27. Emerging Risk Factors Collaboration. Kaptoge S, Di Angelantonio E, Lowe G, Pepys MB, Thompson SG, et al. C-reactive protein concentration and risk of coronary heart disease, stroke, and mortality: an individual participant meta-analysis. Lancet Lond Engl. 2010 Jan 9;375(9709):132-40.

28. Nordberg LB, Lillegraven S, Aga A-B, Sexton J, Olsen IC, Lie E, et al. Comparing the disease course of patients with seronegative and seropositive rheumatoid arthritis fulfilling the 2010 ACR/EULAR classification criteria in a treat-to-target setting: 2-year data from the ARCTIC trial. RMD Open. 2018;4(2):e000752.

29. Pfeifle R, Rothe T, Ipseiz N, Scherer HU, Culemann S, Harre U, et al. Regulation of autoantibody activity by the IL-23-TH17 axis determines the onset of autoimmune disease. Nat Immunol. 2017 Jan;18(1):104-13.

30. Arts EE, Fransen J, Den Broeder AA, van Riel PLCM, Popa CD. Low disease activity (DAS28 $\leq 3.2$ ) reduces the risk of first cardiovascular event in rheumatoid arthritis: a time-dependent Cox regression analysis in a large cohort study. Ann Rheum Dis. 2017 Oct;76(10):1693-9.

31. Singh S, Fumery M, Singh AG, Singh N, Prokop LJ, Dulai PS, et al. Comparative Risk of Cardiovascular Events With Biologic and Synthetic Disease-Modifying Antirheumatic Drugs in 
Patients With Rheumatoid Arthritis: A Systematic Review and Meta-Analysis. Arthritis Care Res. 2020 Apr;72(4):561-76.

\section{Figures}

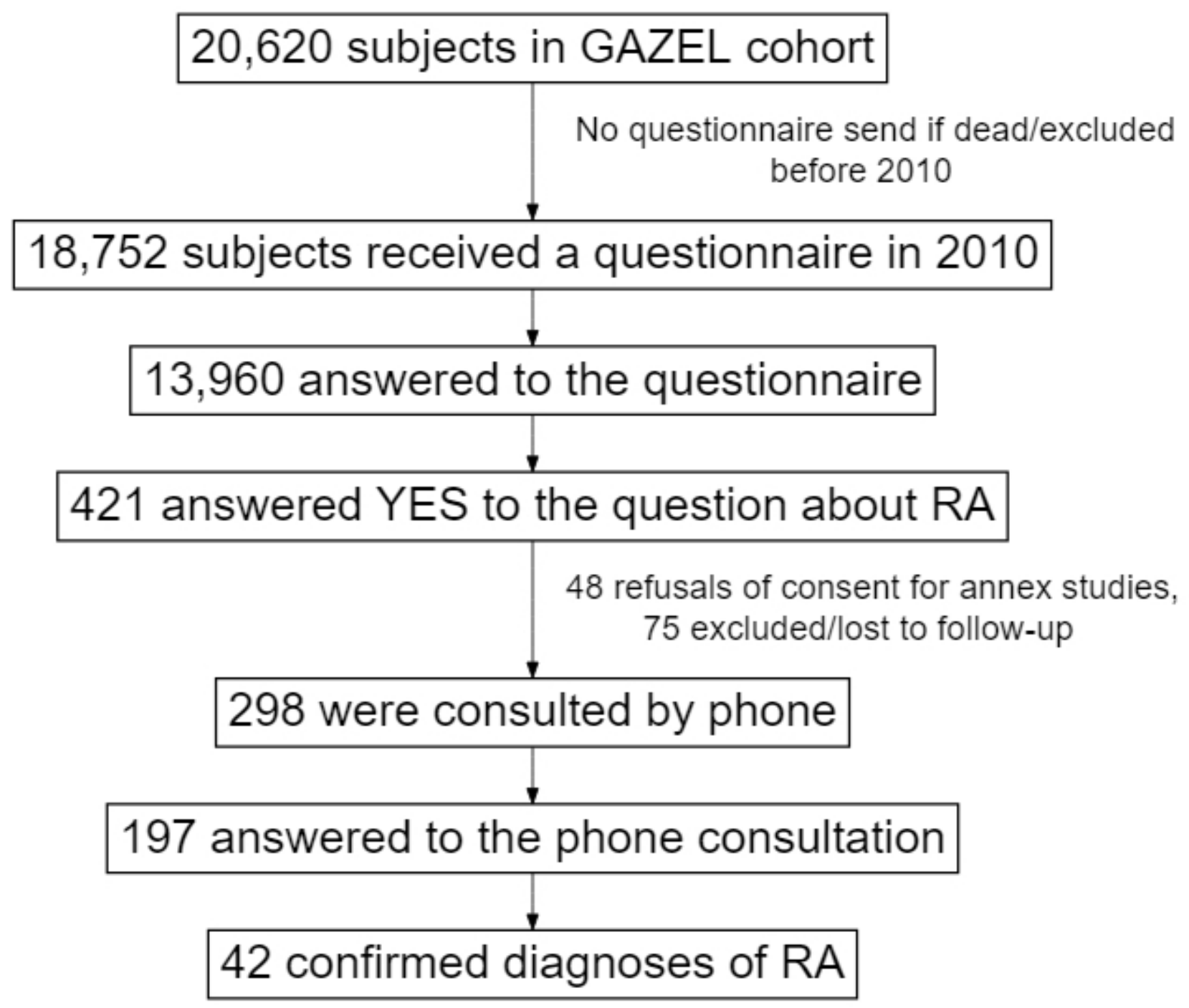

Figure 1

Flowchart of the rheumatoid arthritis (RA) diagnosis confirmation process

\section{Supplementary Files}

This is a list of supplementary files associated with this preprint. Click to download.

- Additionnalfile1.docx 